\title{
PRESENTACIÓN EN TIEMPO DE LA PETICIÓN ANTE LA COMISIÓN INTERAMERICANA DE DERECHOS HUMANOS*
}

\section{Andrés González Serrano**}

Fecha de recibido: 17 de diciembre de 2013

Fecha de aprobado: 27 de febrero de 2014

Artículo resultado de Investigación

Forma de citación: González, A. (2014). Presentación en tiempo de la petición ante la Comisión Interamericana de Derechos Humanos. Revista Prolegómenos. Derechos y Valores, 17, 33, 57-76.

\begin{abstract}
Resumen
Este artículo aborda y analiza el término convencional y reglamentario de los seis meses que se debe tener en cuenta al momento de presentar una petición ante la Comisión Interamericana de Derechos Humanos. A partir del desarrollo de una investigación básica, descriptiva y deductiva se obtiene el resultado de este análisis, el cual permite abordar la siguiente pregunta: ¿cómo debe entenderse el plazo de los seis meses que tienen las víctimas para presentar una petición ante la Comisión Interamericana?; el objetivo general consiste en identificar las líneas de argumentación de la Comisión cuando un Estado propone la inadmisibilidad de la petición por presentación extemporánea.
\end{abstract}

\section{Palabras Claves:}

Comisión Interamericana, admisibilidad, presentación en tiempo, agotamiento de los recursos internos, plazo razonable.

\section{TIMELY SUBMITTION OF A PETITION BEFORE THE INTER-AMERICAN COMMISION ON HUMAN RIGHTS}

\begin{abstract}
The article addresses and analyzes the conventional and statutory limit of six months that must be taken into account when submitting a petition before the Inter-American
\end{abstract}

\footnotetext{
Este artículo pertenece a la investigación denominada «Comisión Interamericana. Aspectos Procedimentales» del grupo de Derecho Público; línea de investigación sobre Derechos Humanos y Derecho Internacional Humanitario, que se adelanta en el Centro de Investigaciones Jurídicas, Políticas y Sociales de la Facultad de Derecho de la Universidad Militar Nueva Granada.

** Docente de la Universidad Militar Nueva Granada. Investigador del grupo de «Derecho Público» y de la línea de «Derechos Humanos y Derecho Internacional Humanitario» del Centro de Investigaciones Jurídicas, Políticas y Sociales de la Facultad de Derecho de la Universidad Militar Nueva Granada. Abogado Magna Cum Laudem de la Universidad Militar Nueva Granada (Colombia). Especialista en Docencia Universitaria y Magister en Derecho Administrativo de la Universidad Militar Nueva Granada (Colombia). Magister en Protección Internacional de Derechos Humanos de la Universidad de Alcalá (España). Estudiante de doctorado en la Universidad de Alcalá (España). Correo electrónico andres.gonzalez@unimilitar.edu.co.
} 
Commission on Human Rights. Through the development of a basic, descriptive and deductive research, it obtains an analysis result that addresses the following question: how the six-month period that the victims have to submit a petition to the InterAmerican Commission should be understood? The general objective is to identify the argumentation lines of the Commission when a State proposes the inadmissibility of the petition because of untimely submission.

\title{
Keywords:
}

Inter-American Commission, admissibility, timely submission, exhaustion of domestic remedies, reasonable period.

\section{APRESENTAÇÃO NO TEMPO DA PETIÇÃO ANTE A COMISSÃO INTERAMERICANA DE DIREITOS HUMANOS}

\begin{abstract}
Resumo
Os endereços e avalia o limite convencional e legal de seis meses que deve ser levado em consideração ao apresentar uma petição perante a Comissão Interamericana de Direitos Humanos. Através do desenvolvimento de uma pesquisa básica, descritivo e dedutivo, ele obtém um resultado de análise que aborda a seguinte questão: como o período de seis meses que as vítimas têm de apresentar uma petição à Comissão Interamericana deve ser entendido? O objetivo geral é identificar as linhas de argumentação da Comissão, quando um Estado se propõe a inadmissibilidade da petição por causa da apresentação intempestiva.
\end{abstract}

\section{Palavras-Chave:}

Comissão Interamericana, Admissibilidade, Apresentação atempada, Esgotamento dos recursos internos, Prazo razoável.

\section{INTRODUCCIÓN}

«Presentación en tiempo de la petición ante la Comisión Interamericana de Derechos Humanos», hace parte del proyecto «Comisión Interamericana de Derechos Humanos. Aspectos Procedimentales». Esta investigación pretende abordar y dar solución a la siguiente pregunta: ¿cuál ha sido la línea argumentativa en las decisiones de la Comisión Interamericana de Derechos Humanos en materia de procedibilidad?

El proyecto se construye sobre la necesidad de continuar con la tarea académica de determinar y establecer los diferentes espacios convencio- nales procedimentales; identificar y construir nichos citacionales; $y$ crear líneas jurisprudenciales que permitan acercar a los defensores de los derechos humanos a la forma como la Comisión Interamericana de Derechos Humanos aplica e interpreta los requisitos de procedibilidad establecidos en la Convención Americana sobre Derechos Humanos, en el sistema de peticiones individuales e interestatales.

Hasta la fecha no se conoce de alguna iniciativa que pretenda abordar el tema objeto de estudio de la manera propuesta, lo que dificulta aún más el acceso al sistema interamericano de derechos humanos; es por ello que este 
proyecto constituye un aporte al fortalecimiento y legitimidad del sistema interamericano. Sin embargo, es importante resaltar que la Comisión Interamericana de Derechos Humanos, a través de sus informes de admisibilidad $e$ inadmisibilidad, ha interpretado los requisitos de admisibilidad de una petición, los cuales han sido de recibo doctrinal, entre otros, por Barbosa (2002), Faúndez (2004), Medina \& Nash (2011), Rey (2005), Martin \& Rodríguez (2006); no obstante, su trabajo se ha centrado en acercar $y$ explicar el funcionamiento del sistema interamericano, y no en la estrategia metodológica de crear espacios convencionales, nichos citacionales y líneas jurisprudenciales.

La estrategia metodológica desarrollada en esta investigación permitirá abordar el objetivo general y los objetivos específicos, es decir, se podrá identificar y analizar de forma específica los requisitos de competencia en razón a la materia, tiempo, persona y lugar, y los requisitos de admisibilidad, como agotamiento de recursos internos, hechos que caractericen una violación, no pleito pendiente internacional y presentación en tiempo de la petición, último requisito que será objeto de análisis.

Cuando se inicia una petición individual (González, 2014), interestatal o de oficio, será trasladada al Estado parte de la Convención Americana para que la conteste en un término de tres meses prorrogables a cuatro meses (Reglamento de la CIDH, artículo 33-3, 2013). En su escrito de contestación podrá presentar observaciones a la admisibilidad de la petición (Reglamento de la CIDH, artículo 33-6, 2013), entre ellos, que fue presentada de forma extemporánea. Sin embargo, los legitimados por activa deberán velar por el cumplimiento del término convencional de los «seis meses» (Convención Americana, artículo 46-1-b, 1969) o del reglamentario del "plazo razonable" (Reglamento de la CIDH, artículo 32-2, 2013).

En otros términos, el peticionario, que podrá ser cualquier persona, un grupo de personas, una entidad no gubernamental reconocida en uno o más estados miembros de la Organización de Estados Americanos, un estado parte de la Convención Americana o la Comisión Interamericana, deberá velar porque la petición sea presentada, dentro de los seis meses siguientes a la notificación, a la presunta víctima de la decisión definitiva que agote la jurisdicción interna o en un plazo razonable, cuando la presunta víctima no tenga la obligación de agotar los recursos internos.

El término de los seis meses será analizado en el presente artículo en los siguientes cinco capítulos: (1) Observaciones preliminares; (2) Certidumbre y estabilidad jurídica; (3) ¿Qué debe entenderse por decisión definitiva?; (4) Notificación, y (5) ¿Desde qué momento se tiene como recibida la petición? Así mismo, se hará una deducción y creación de nichos citacionales ${ }^{1}$, a partir de los treinta y ocho informes de admisibilidad $e$ inadmisibilidad que la Comisión Interamericana ha proferido desde el año 2005 hasta el 2011, en los cuales el órgano cuasi jurisdiccional se ha pronunciado sobre la objeción estatal de presentación extemporánea de la petición.

\section{OBSERVACIONES PRELIMINARES}

El requisito de admisibilidad denominado «plazo para la presentación de peticiones» o «presentación en tiempo de una petición» se encuentra regulado en la Convención Americana sobre Derechos Humanos (en adelante Convención) y en el Reglamento de la Comisión Interamericana de Derechos Humanos (en adelante Reglamento $\mathrm{CIDH}$ ).

La Convención Americana sobre Derechos Humanos consagra que

«Para que una petición o comunicación presentada conforme a los artículos 44 a 45

1 Conjunto de sentencias que permiten la identificación de puntos nodales de los diferentes espacios convencionales. (López, 2008). 
sea admitida por la Comisión, se requerirá: [...] que sea presentada dentro del plazo de seis meses, a partir de la fecha en que el presunto lesionado en sus derechos haya sido notificado de la decisión definitiva [... ]» (Artículo 46.1.b, 1969).

Entre tanto, el Reglamento de la CIDH establece que

«la Comisión considerará las peticiones presentadas dentro del término de los seis meses contados a partir de la fecha en que la presunta víctima haya sido notificada de la decisión que agota los recursos internos [...]» (Artículo 32.1, 2013).

Plazo convencional que ha sido aplicado e interpretado por la Comisión Interamericana de Derechos Humanos en el caso J.SC.H. y M.G.S, entre otros, en el cual reiteró que para «que la petición pueda ser declarada admisible, es necesario que se haya presentado en el plazo de seis meses en la fecha en que el interesado fuera notificado de la decisión final en la jurisdicción interna» (CIDH, 2009a, párr.84). Específicamente, señaló que el caso era admisible toda vez que constató que la presunta víctima fue notificada de la decisión definitiva dentro de la jurisdicción interna y presentó la petición dentro de los seis meses siguientes.

Al respecto, se observa que la fecha de presentación de la petición ante la Comisión fue el 9 de abril de 2004 y el 9 de octubre de 2003 la presunta víctima fue notificada de la decisión definitiva dentro de la jurisdicción interna. Por lo tanto, la Comisión concluye que el requisito del plazo de los seis meses se encuentra efectivamente cumplido en el presente caso (2009a, párr.86).

Al respecto, la Comisión entiende que la decisión que agotó la jurisdicción interna es el último fallo notificado a la presunta víctima el 23 de octubre de 2003 emitido por el Juzgado Noveno de Distrito y que la fecha de presentación de la petición ante la Comisión fue el 21 de abril de 2004, esto es, dentro del plazo establecido en el artículo 46.1.b de la Convención (2009a, párr.88).

En la siguiente gráfica, se puede observar el nicho citacional que podría generarse desde el espacio convencional denominado «admisibilidad de la petición por el cumplimiento del plazo de los seis meses».

Blanca Olivia Contreras Vital y otros Vs México (2011a, párr. 39)

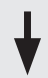

José Castro Ballena y otros Vs Perú (2010a, párr. 40)

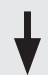

Familia de José Leonardo Abril Armijos Vs. Ecuador (2010b, párr. 44)

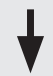

Irineo Martínez Torres y Candelario Martínez Damian Vs México (2010c, párr. 43)

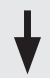

Samanta Nunes Da Silva Vs Brasil (2009b, párr. 42) 


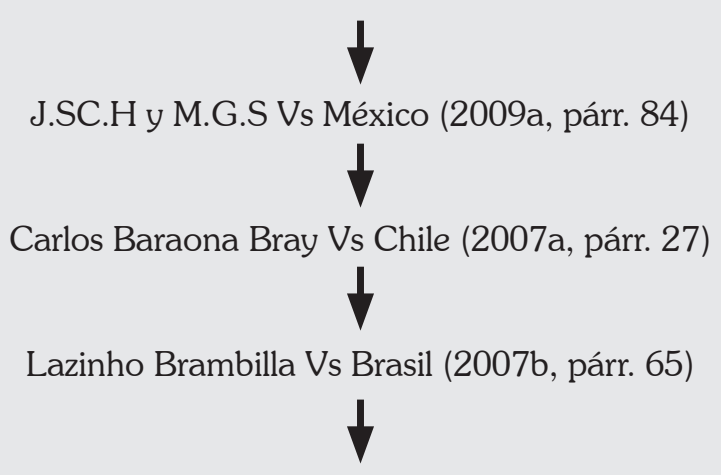

Victor Manuel Ancalaf Llaupe Vs Chile (2007c, párr. 38)

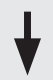

Juan Patricio Marileo Saravia y ortos Vs Chile (2007d, párr. 46)

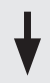

Guillermo Santiago Zaldívar Vs Argentina (2005a, párr. 23)

Fuente: Elaboración propia tomando en cuenta los informes de admisibilidad e inadmisibilidad de la CIDH entre los años 2005 a 2011.

Así mismo, la Comisión declaró inadmisible el caso José Luis Forzzani Ballardo, en aplicación estricta del plazo de los seis meses, debido a que los peticionarios presentaron fuera de término la petición ante la Comisión Interamericana.

El artículo 46.1.b) de la Convención establece que para que la petición pueda ser declarada admisible es necesario que haya sido presentada dentro del plazo de seis meses contados a partir de la fecha en que el interesado fue notificado de la decisión final que agotó la jurisdicción interna (2011b, párr.24).

Conforme a lo señalado en el párrafo 23 supra, los recursos de la jurisdicción interna fueron agotados el 19 de abril de 1996, mediante resolución del Primer Juzgado de Paz Letrado en lo Civil que declaró sin lugar un recurso de apelación deducido por el señor José Luis Forzzani Ballardo. De acuerdo con la información proporcionada por las partes, dicha resolución fue notificada a la presunta víctima el 30 de abril de 1996. Dado que la presente petición fue recibida por la CIDH el $1^{\circ}$ de mayo de 2001, no se encuentra satisfecho el requisito previsto en el artículo 46.1.b) de la Convención Americana (2011b, párr.25).

En la siguiente gráfica, se puede observar el nicho citacional que podría generarse desde el espacio convencional denominado «inadmisibilidad de la petición por el incumplimiento del plazo de los seis meses». 
José Luis Forzzani Ballardo Vs Perú (2011b, párr. 24- 25)

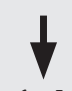

Nelson Aparecido Trindade Vs Brasil (2009c, párr. 28)

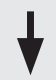

Jesús Vera Roncal, Daniel Zelada Abanto y Evaristo Gálvez Cárdenas Vs Perú

(2008a, párr.34 y 38)

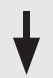

Diego Rafael Jorreto Bonilla Vs Chile (2006a, párr. 22- 23)

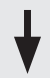

Helio Bicudo Vs. Brasil (2005c, párr. 29 y 32)

Fuente: Elaboración propia tomando en cuenta los informes de inadmisibilidad de la CIDH entre los años 2005 a 2011.

\section{CERTIDUMBRE Y ESTABILIDAD JURÍDICA}

La Comisión Interamericana ha establecido que el plazo de los seis meses tiene la función de garantizar a los peticionarios y a los agentes estatales certidumbre y estabilidad jurídica y credibilidad en el sistema de peticiones individuales $e$ interestatales ante el sistema interamericano de protección de derechos humanos.

En el caso Blanca Olivia Contreras y otros, la Comisión reiteró que una petición será admisible si es presentada dentro de los seis meses siguientes a la notificación de la decisión definitiva que agota la jurisdicción interna. Además, constató que las presuntas víctimas fueron notificadas así: Blanca Olivia Contreras Vital, 23 de junio de 2005; José Antonio Martínez Jiménez, 9 de marzo de 2003; Roberto Clemente Álvarez Alvarado, 19 de abril de 2004; Juan Gerardo Murillo Murillo, 12 de febrero de 2003 y José Eduardo Martínez de Luna, 7 de diciembre de 2003 (2011a, párr. 41), y que la petición fue presentada el 9 de junio de 2004. Con fundamento en lo anterior, la CIDH declaró la admisibilidad del caso en relación con los peticionarios Blanca Olivia y Roberto Clemente, debido a que solo ellos cumplieron con el plazo convencional, y con la garantía de la certidumbre y estabilidad jurídica.(2011a, párr. 42).

De la misma forma, en el caso Nelson Aparecido Trindade, la Comisión se refirió al doble propósito que tiene el término de los seis meses. Por un lado, asegurar la certidumbre, estabilidad jurídica y credibilidad en el sistema de peticiones, $y$, por otro, proporcionar a la persona -peticionario y/o víctima- involucrada tiempo suficiente para considerar su posición (2009c, párr.26). Declarando, así, inadmisible el caso, toda vez que la petición fue presentada el 27 de abril de 2004, y la presunta lesionada tenía conocimiento de la decisión definitiva desde el 7 de julio de 2003, es decir, supero el término convencional de los seis meses.

En la siguiente gráfica, se puede observar el nicho citacional que podría generarse desde el espacio convencional denominado «certidumbre y estabilidad jurídica de los seis meses». 
Blanca Olivia Contreras Vital y otros Vs México (2011a, párr. 39)

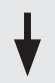

Irineo Martínez Torres y Candelario Martínez Damian Vs México (2010c, párr. 43)

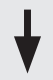

Nelson Aparecido Trindade Vs. Brasil (2009c, párr. 25)

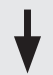

Luis Gonzalo "Richard” Vélez Restrepo y Familia Vs Colombia (2008b, párr. 81)

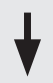

Jesús Mónica Feria Tinta Vs Perú (2008c, párr. 62)

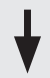

Marcela Alejandra Porco Vs Bolivia (2008d, párr. 64)

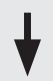

Guillermo Santiago Zaldívar Vs Argentina (2005a, párr. 23.)

Fuente: elaboración propia tomando en cuenta los informes de admisibilidad e inadmisibilidad de la CIDH entre los años 2005 a 2011.

No obstante, la Comisión Interamericana de Derechos Humanos se apartó de la aplicación estricta del plazo de los seis meses, el cual había sido contado de forma rigurosa desde la notificación al presunto lesionado de la decisión definitiva que agota la jurisdicción interna hasta la presentación de la petición ante la Comisión.

Lo anterior, se presentó en el caso Enrique Hermann Pfister Frías y Lucrecia Pfister Frías en el cual el Estado de Argentina objetó la admisibilidad de la petición y solicitó a la Comisión que profiriera un informe de inadmisibilidad con el argumento de que los peticionarios habían presentado la petición fuera del plazo convencional, toda vez que el término de los seis meses había sido superado en un día. Sin embargo, la Comisión declaró la admisibilidad del caso y rechazó el argumento estatal, y reiteró que el sistema procesal es un medio para alcanzar la justicia y que esta no puede ser sacrificada en aras de meras formalidades (2010d, párr.43).

Conforme al artículo 46(1) (b) de la Convención Americana constituye un requisito de admisibilidad la presentación de las peticiones dentro del plazo de seis meses a partir de la notificación al presunto lesionado de la sentencia que agote los recursos internos. En el presente caso, consta en el expediente que los peticionarios fueron notificados de la decisión definitiva el 28 de octubre de 1997 y la petición fue presentada en la Oficina Nacional de Enlace de la Organización de los Estados Americanos en Buenos Aires el 29 de abril de 1998, es decir, un día después del plazo previsto en la Convención. Al respecto, 
los órganos del sistema interamericano de protección de derechos humanos han destacado en diferentes ocasiones que es un principio comúnmente aceptado que el sistema procesal es un medio para alcanzar la justicia y que ésta no puede ser sacrificada en aras de meras formalidades (2010d, párr.43).

El Estado alegó que los peticionarios presentaron el caso por fuera del plazo razonable. Al respecto, la Comisión advierte que de conformidad con el artículo 32 de su reglamento: «En los casos en los cuales resulten aplicables las excepciones al requisito del previo agotamiento de los recursos internos, la petición deberá presentarse dentro de un plazo razonable». De acuerdo con lo anterior, $y$ teniendo en cuenta que en el presente caso la Comisión no ha establecido que resulten aplicables las excepciones al requisito del previo de los recursos internos, no corresponde analizar si la petición se presentó en un plazo razonable. En consecuencia, la Comisión considera que se ha cumplido con el requisito consagrado en el artículo 46(1)(b) de la Convención (2010d, párr.44).

En la siguiente gráfica, se puede observar el nicho citacional que podría generarse desde el espacio convencional denominado «el sistema procesal es un medio para alcanzar la justicia y que ésta no puede ser sacrificada en aras de meras formalidades».

Enrique Hermann Pfister Frías y Lucrecia Pfister Frías Vs Argentina (2010d, párr. 43)

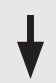

Agustín Bladimiro Zegarra Vs Perú (2009d, párr. 66)

Fuente: elaboración propia tomando en cuenta los informes de admisibilidad e inadmisibilidad de la CIDH entre los años 2005 a 2011.

Sin embargo, las dos posiciones de la Comisión Interamericana de Derechos Humanos consisten, por un lado, en garantizar certidumbre y estabilidad jurídica, $y$, por otro, aducen que el sistema procesal es un medio para alcanzar la justicia y que esta no puede ser sacrificada en aras de meras formalidades, puede ser interpretada como una debilidad del sistema de peticiones individuales.

No obstante, es claro que si la petición es presentada dentro de los seis meses siguientes a la notificación a la presunta víctima de la decisión definitiva que agota la jurisdicción interna, no habrá duda en el cumplimiento de este plazo convencional. Pero la anterior certeza no se presentó, y podrá ser objeto de confusión, debido a que en los casos «Enrique Hermann Pfister Frías y Lucrecia Pfister Frías» -en el cual se había vencido el termino en un día- y «Agustín Bladimiro Zegarra» -en el cual se había vencido el termino en once días-, la Comisión señaló que no podría sacrificar la justicia por meras formalidades.

\section{¿QUÉ DEBE ENTENDERSE POR DECISIÓN DEFINITIVA?}

Es importante señalar que para que sea admisible una denuncia presentada ante la Comisión Interamericana es necesario que se hayan intentado 
y agotado los recursos internos, conforme a los principios del derecho internacional generalmente reconocidos, siempre y cuando en el sistema nacional estén efectivamente disponibles y sean adecuados y eficaces para remediar la violación.

No obstante, las víctimas no tendrán que agotar los recursos internos cuando: (1) no exista en la legislación interna el debido proceso legal para la protección del derecho en cuestión; (2) no se haya permitido el acceso a los recursos; (3) haya sido impedidos de agotarlos; y (4) haya retardo injustificado en la decisión. Estas causales permitirán a la Comisión Interamericana, en el análisis de admisibilidad de una petición individual o interestatal, aplicar el criterio del plazo razonable y no el término de los seis meses.

El término de los seis meses, como se indicó, genera certidumbre y estabilidad jurídica a los peticionarios y agentes estatales, y deberán ser contados a partir de la notificación, al presunto lesionado o presunta víctima, de la decisión interna definitiva, la cual debe ser entendida como la que agota la jurisdicción interna, es decir, como aquel recurso que da certeza a la presunta víctima sobre la garantía o no de su derecho humano violado a nivel nacional.

La víctima tendrá la obligación de agotar el recurso que tiene la capacidad de proteger, por mandato legal e interpretación jurisprudencial, el derecho humano alegado, es decir, la acción adecuada que posee la facultad de resolver la situación jurídica que se imputa infringida por el Estado y que tiene la potestad de remediarla y revertirla.

En otros términos, si el presunto lesionado o presunta víctima agota el recurso que no es idóneo, se tendrá por no agotada la jurisdicción interna y su notificación no será considerada para el cómputo del plazo convencional y reglamentario de los seis meses.

Al respecto, la Comisión observa que conforme a la legislación procesal peruana aplicable, el «Recurso de Aclaración» no tiene un carácter impugnatorio, toda vez que el juzgador no está en capacidad de alterar el contenido sustancial de una decisión en virtud de este recurso. El recurso se limita a brindar la oportunidad a las partes de que se aclare algún concepto oscuro o dudoso expresado en la parte resolutoria de la decisión que pone fin a la instancia judicial. Así se desprende de la legislación pertinente $y$ de la doctrina pacífica establecida tanto por la Corte Suprema Justicia como por el Tribunal Constitucional peruano (CIDH, 2008a, párr. 33).

En efecto, la Comisión observa que el recurso a que refieren los peticionarios no tenía entidad jurídica para revertir la situación alegada como violatoria. Al haber la Corte Suprema de Justicia emitido una decisión sobre el fondo del asunto negando las pretensiones de los peticionarios, el recurso de aclaración no era idóneo para perseguir la decisión jurídica buscada por éstos, es decir, recurrir o cuestionar la decisión. [...] (CIDH, 2008a, párr. 34).

Por otra parte, la Comisión observa que la sentencia de la Corte Suprema que decidió sobre el fondo del asunto fue notificada a los peticionarios el 11 de abril de 2000 y que la petición fue recibida en la Secretaría Ejecutiva de la Comisión el 29 de noviembre de 2000, es decir, fuera del plazo establecido en el artículo 46.1.b de la Convención (CIDH, 2008a, párr. 35).

Por las razones antes expuestas, la Comisión considera que el recurso de "Aclaración e Interpretación" interpuesto por los peticionarios ante la Corte Suprema de Justicia de Perú, el 5 de mayo de 2000, resulta inapropiado para resolver la situación jurídica infringida. La Comisión considera igualmente que dicha iniciativa no constituye un recurso jurisdiccional en el sentido del artículo 46.1. a de la Convención Americana (CIDH, 2008a, párr. 36). 
En consecuencia de lo anterior, la interposición de la solicitud de aclaración e interpretación efectuada por los peticionarios no difirió el inicio del plazo de seis meses contemplado en los artículos 46.1.b de la Convención Americana y 32 del Reglamento de la $\mathrm{CIDH}$, el cual debe computarse a par- tir de la sentencia definitiva de fecha 7 de marzo de 2000 (CIDH, 2008a, párr. 37).

En la siguiente gráfica, se puede observar el nicho citacional que podría generarse desde el espacio convencional denominado «calidad de la decisión para contar el plazo de los seis meses».

Jesús Vera Roncal, Daniel Zelada Abanto y Evaristo Gálvez Cárdenas Vs. Perú (2008a, párr. 32)

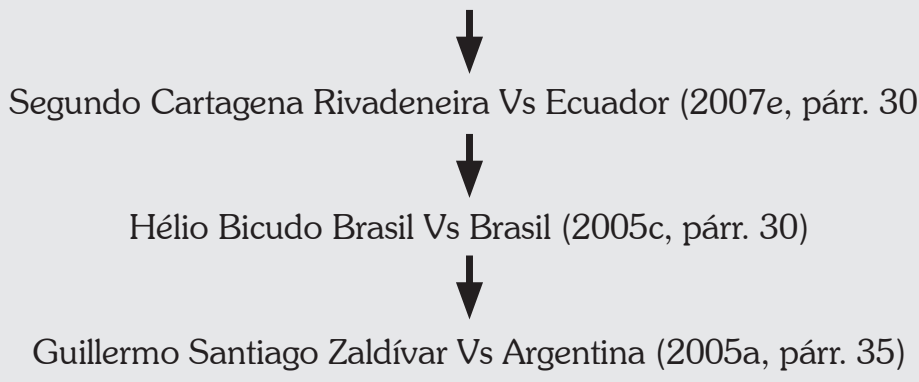

Fuente: elaboración propia tomando en cuenta los informes de admisibilidad e inadmisibilidad de la CIDH entre los años 2005 a 2011.

Si bien, el precedente de los órganos que protegen los derechos humanos en el sistema interamericano ha sido reiterativo en establecer que el recurso a agotar por la presunta víctima o lesionado es el adecuado e idóneo, la Comisión Interamericana de Derechos Humanos manifestó que la víctima podrá agotar el recurso con posibilidades de efectividad.

Lo anterior, lo reiteró en el caso Guillermo Santiago Zaldívar, en el cual valoró los diferentes recursos agotados en la jurisdicción argentina, y consideró que agotar un recurso extraordinario y el de casación, para el caso específico, satisfacía la admisibilidad de la petición.

A la fecha en que el señor Zaldívar fue procesado, el sistema procesal preveía una primera instancia, seguida de una instancia de apelación. La instancia de apelación podía ser invocada por el acusado condenado en primera instancia o por el fiscal o el querellante que no hubiera podido obtener una condena. En casos tales como el del señor Zaldívar, en que la condena fue por primera vez pronunciada en instancia de apelación, el sistema procesal preveía sólo una posible vía de impugnación: el recurso extraordinario, al amparo del artículo 14 de la Ley 48 del Código Nacional de Proceso Civil y Comercial. La naturaleza del recurso se limitaba a ciertas cuestiones de derecho y estaba sujeta a pedido de venia. En el presente caso, la venia fue concedida por el tribunal que pronunció la sentencia, pero el recurso fue rechazado por inadmisible por el tribunal superior (CIDH, 2005a, párr. 36).

Los peticionarios luego procuraron invocar el recurso de casación. Aunque ese recurso no estaba previsto en el sistema procesal al amparo del cual él había sido 
juzgado, los peticionarios entendieron que, dada la condición de Argentina de Estado Parte de la Convención Americana y dado que en la Constitución de 1994 se había otorgado a dicho instrumento supremacía frente a la legislación interna, se justificaba invocar otro mecanismo procesal para obtener una revisión de la condena del señor Zaldívar (CIDH, 2005a, párr. 37).

Dado que el acceso a una revisión por una instancia superior es precisamente una de las materias en cuestión en el presente caso, la Comisión concluye que no era irrazonable que los peticionarios intentaran invocar el recurso extraordinario y el recurso de casación, en su empeño por obtener esa segunda instancia. Aunque el recurso de casación fue rechazado por inaplicable en todas las instancias, la Comisión observa que el fiscal de la Cámara de Casación consideró que debió haber sido aceptada en base al derecho a apelar las sentencias establecido por la Convención Americana y al hecho de que el señor Zaldívar no había podido obtener ninguna revisión de los méritos de sus denuncias. La Comisión también observa que, dada la supremacía asignada a las obligaciones impuestas por la Convención Americana en la Constitución de 1994[3], no era irrazonable que los peticionarios invocaran un recurso que consideraron correspondía a un derecho protegido por la Convención. Además, dado que la interposición de la petición ante el sistema interamericano es un mecanismo complementario, tampoco era irrazonable que los peticionarios recurrieran a estos mecanismos procesales alternativos para asegurar que el Estado tuviera plena oportunidad de considerar y resolver sus denuncias antes de invocar los mecanismos internacionales de protección. En consecuencia, la Comisión considera que la presentación de la petición, recibida el 29 de octubre de 1999, satisface el requisito de presentación dentro de los seis me- ses siguientes de la notificación de la sentencia definitiva (CIDH, 2005a, párr. 39).

Esta decisión genera un efecto directo para el cumplimiento de los seis meses que tiene el peticionario para presentar una petición ante la Comisión Interamericana. Es decir, se abre la opción que a partir de la notificación a la presunta víctima del recurso que tiene posibilidad de efectividad, se comience a contar el plazo convencional establecido en el artículo 46.1b.

\section{NOTIFICACIÓN}

La Convención Americana señala que el plazo convencional de los seis meses no se inicia a contar desde la fecha de expedición de la decisión que agota la jurisdicción interna, sino desde la fecha que notifican a la víctima -presunto lesionado- de la decisión definitiva que decide de fondo proteger o no sus derechos humanos en la jurisdicción nacional. Tampoco será de recibo el contar los seis meses desde la notificación de un recurso que no tenga la calidad de ser adecuado y efectivo para proteger el derecho humano alegado violado.

Un ejemplo de lo anterior, es el informe de admisibilidad del caso Héctor Fidel Cordero Bernal, en el cual la Comisión señaló:

Conforme a lo señalado en el párrafo 25 supra, los recursos de la jurisdicción interna fueron agotados a través de la resolución del Tribunal Constitucional de 8 de mayo de 1998. La información presentada por las partes indica que esa decisión fue notificada a la presunta víctima el 31 de julio de 1998. Dado que la presente petición fue recibida por la CIDH el 11 de noviembre de 1998, la misma satisface el requisito de admisibilidad previsto en el artículo 46.1.b) de la Convención (2011c, párr. 27).

En la siguiente gráfica, se puede observar el nicho citacional que podría generarse desde el espacio convencional denominado «notificación de la decisión definitiva y su relación con el plazo de los seis meses». 
Wilbert Apaza Vargas Vs. Perú (2011c, párr. 31)

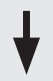

Héctor Fidel Cordero Bernal Vs. Perú (2011d, párr.26)

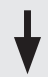

José Luis Forzzani Ballardo Vs. Argentina (2011b, párr.24)

$\downarrow$

Blanca Olivia Contreras Vita y otros Vs México (2011a, párr.39)

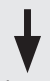

Luis Eduardo Guachalá Chimbó Vs. Ecuador (2010e, párr. 38)

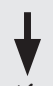

Irineo Martínez Torres y Candelario Martínez Damian Vs México (2010c, párr. 43)

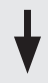

Samanta Nunes Da Silva Vs Brasil (2009b, párr. 42)

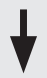

J.SCH. y M.G.S Vs México (2009a, párr. 84)

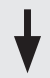

Jesús Mónica Feria Tinta Vs. Perú (2008c, párr. 62)

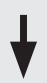

Marcela Alejandra Porco Vs. Bolivia (2008d, párr. 64)

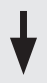

Lazinho Brambilla Vs Brasil (2007b, párr.65.)

Fuente: elaboración propia tomando en cuenta los informes de admisibilidad e inadmisibilidad de la CIDH entre los años 2005 a 2011.

Por otro lado, la Comisión amplió el concepto de notificación, considerando que el plazo de los seis meses no solo puede ser contabilizado a partir de la notificación de la decisión definitiva al presunto lesionado, sino que se puede iniciar a contar desde el momento en el que la presunta víctima tenga conocimiento de la decisión definitiva (CIDH, 2009c, párr. 25). Este criterio fue aplicado en el caso Nelson Aparecido Trindade, en el cual el peticionario manifestó que la petición se presentó en tiempo, debido a que la viuda de la víctima se notificó solo hasta noviembre de 2003 de la decisión de archivo de la investigación policial dictada el 6 de diciembre de 2002, y que al presentarse la petición ante la Comisión el 27 de abril de 2004 se encontraría dentro del plazo de los seis meses (CIDH, 2009c, párr.26).

A su turno, Brasil señaló que la denuncia fue presentada vencido el plazo de los seis meses, ya que el peticionario tenía conocimiento de la decisión de archivo desde el 7 de julio de 2003, y que al presentarla ante la Comisión el 27 de abril de 2004 
se encontraba caducado el plazo convencional para presentarla (CIDH, 2009c, párr.26).

Así mismo, la Comisión ha señalado que la carga procesal de demostrar la fecha de la notificación o del conocimiento de la decisión definitiva en el análisis de admisibilidad ante la Comisión le corresponde al Estado, cuando la presunta víctima o peticionario manifieste que no ha recibido notificación por parte del ente encargado de emitirla. (2010b, párr. 33)

Carga procesal aplicada al Estado de Ecuador en el caso de la Familia de José Leonardo Abril Armijos, en el cual, la Comisión reconoció que recibió la petición el 16 de octubre de 2002 y la última decisión adoptada en el fuero interno fue dictada el 25 de marzo de 2002 (2010b, párr. 34). Tiempo, que excedía en 21 días el término convencional, sin embargo, el peticionario alegó que tuvo conocimiento solo hasta octubre de 2003 de la decisión definitiva.

\section{(...) la Comisión observa que el Estado no ha controvertido el alegato del peticionario respecto de la ausencia de notificación de dicha decisión, y no ha presentado docu- mentación respecto a la notificación de la misma, por lo tanto la Comisión considera que debe darse por satisfecho el requisito de admisibilidad referente al plazo de pre- sentación (2010c, párr. 34).}

En la siguiente gráfica, se puede observar el nicho citacional que podría generarse desde el espacio convencional denominado «conocimiento de la decisión definitiva en relación con el plazo de los seis meses».

Familia de José Leonardo Abril Armijos Vs Ecuador (2010b, párr.34)

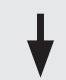

Nelson Aparecido Trindade Vs. Brasil (2009c, párr. 26)

Fuente: elaboración propia tomando en cuenta los informes de admisibilidad e inadmisibilidad de la CIDH entre los años 2005 a 2011.

\section{DESDE QUÉ MOMENTO SE TIENE COMO RECIBIDA LA PETICIÓN}

Como se indicó, y así está consagrado en la Convención y reglamento de la Comisión, los peticionarios cuentan con el plazo de seis meses para presentar una petición ante la Comisión Interamericana. Sin embargo, el término para su presentación ha sido de debate en el mecanismo de petición individual ante la Comisión por parte de los peticionarios y agentes estatales. Estos últimos, han objetado la admisibilidad de la petición, con el argumento, entre otros, de que los seis meses deben ser contados desde el momento en que la Comisión le hace el traslado al Estado para que presente sus objeciones a la admisibilidad de la petición (CIDH, 2007a, párr. 49).

No obstante, la Comisión Interamericana en el análisis de diferentes peticiones ha sido clara al indicar que los seis meses se contaran desde la fecha en que el presunto lesionado en sus derechos haya sido notificado de la decisión definitiva hasta que es presentada ante la Comisión Interamericana. Y que no es de recibo el alegato estatal que el término debe correr a partir del traslado de la petición al Estado (2007b, párr. 41).

El criterio anterior fue aplicado en el caso Carlos Baraona Bray, en cual el Estado de Chile solicitó la inadmisibilidad de la petición por su 
presentación extemporánea, sin embargo la Comisión indicó:

El artículo 46.1.b de la Convención Americana establece que uno de los requisitos de admisión de una petición es que deberá ser "presentada dentro del plazo de seis meses, a partir de la fecha en que el presunto lesionado en sus derechos haya sido notificado de la decisión definitiva" (2007a, párr. 28).

El Estado argumenta que la petición es inadmisible porque le fue notificada por la Secretaría Ejecutiva de la CIDH el 15 de septiembre de 2005, en su parecer, fuera del plazo establecido en los artículos 46.1.b y 47.a de la Convención y 32.1 del Reglamento de la Comisión (2007a, párr. 29).

La CIDH desestima el argumento del Estado de Chile en atención a que el plazo de seis meses establecido en el artículo 46.1.b de la Convención se cuenta desde la fecha en que el presunto lesionado en sus derechos fue notificado de la decisión definitiva hasta que es presentada ante la CIDH y no hasta que la petición es transmitida al Estado respectivo (2007a, párr. 30).

Tal como fue señalado anteriormente, el 9 de septiembre de 2004 la Corte Suprema de Chile notificó a la presunta víctima de la decisión que negó el recurso de nulidad, la cual no es susceptible de revisión. De acuerdo a lo establecido en el artículo 46.1.b de la Convención, el plazo para presentar una petición ante la CIDH vencía el 9 de marzo de 2005. En el presente caso, la petición fue recibida por la $\mathrm{CIDH}$ el 4 de marzo de 2005 (2007a, párr. 31).

Por ende, la CIDH concluye que la petición cumple con el requisito establecido en el artículo 46.1.b de la Convención Americana (2007a, párr. 32).

En la siguiente gráfica, se puede observar el nicho citacional que podría generarse desde el espacio convencional denominado «el plazo de los seis meses se cuentan desde la fecha en que el presunto lesionado en sus derechos fue notificado de la decisión definitiva hasta que es presentada ante la Comisión».

Carlos Baraona Bray Vs. Chile (2007a, párr. 30)

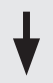

Víctor Manuel Ancalaf Llaupe Vs. Chile (2007c, párr. 41)

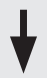

Juan Patricio Marileo Saravia y Otros Vs. Chile (2007d, párr. 49)

Fuente: elaboración propia tomando en cuenta los informes de admisibilidad e inadmisibilidad de la CIDH entre los años 2005 a 2011.

De la misma forma, ha generado debate la pregunta desde cuándo se debe entender como presentada una petición ante el órgano cuasi judicial del sistema interamericano. Sin embargo, la Comisión ha establecido, conforme a la convención y a su reglamento, que se tendrá por presentada cuando es recibida por la Comisión (2007a, párr. 30 y 31; 2007b, párr. 40 y 41; 2007c, párr. 48 y 49).

En la siguiente gráfica, se puede observar el nicho citacional que podría generarse desde el espacio convencional denominado «recibo de la petición por la Comisión Interamericana». 
Wilbert Apaza Vargas Vs. Perú (2011c, párr. 31)

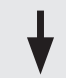

Héctor Fidel Cordero Bernal Vs. Perú (2011d, párr.26)

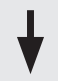

José Luis Forzzani Ballardo Vs. Argentina (2011b, párr.24)

$\downarrow$

Blanca Olivia Contreras Vita y otros Vs México (2011a, párr.39)

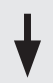

Luis Eduardo Guachalá Chimbó Vs. Ecuador (2010e, párr. 38)

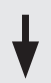

Irineo Martínez Torres y Candelario Martínez Damian Vs México (2010c, párr. 43)

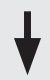

Samanta Nunes Da Silva Vs Brasil (2009b, párr. 42)

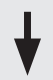

J.SCH. y M.G.S Vs México (2009a, párr. 84)

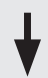

Jesús Mónica Feria Tinta Vs. Perú (2008c, párr. 62)

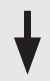

Marcela Alejandra Porco Vs. Bolivia (2008d, párr. 64)

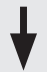

Carlos Baraona Bray Vs. Chile (2007a, párr. 30)

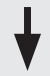

Lazinho Brambilla Vs Brasil (2007b, párr.65)

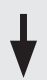

Víctor Manuel Ancalaf Llaupe Vs. Chile (2007c, párr.40)

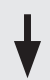

Juan Patricio Marileo Saravia y Otros Vs. Chile (2007d, párr. 48)

Fuente: elaboración propia tomando en cuenta los informes de admisibilidad e inadmisibilidad de la CIDH entre los años 2005 a 2011. 
No obstante lo anterior, la Comisión en dos casos -bajo el espacio de análisis 2005 a 201ha establecido que el término de los seis meses no incluye los días que la petición se encuentra en poder de la agencia de correo postal, es decir, que se toma como fecha de recibo por parte de la Comisión Interamericana el día que los peticionarios la enviaron por correo (2008c, párr.45). De la misma forma, la Comisión en el caso Samanta Nunes Da Silva Vs Brasil indicó:

El artículo 46(1)(b) de la Convención Americana establece que toda petición debe presentarse dentro de un plazo de seis meses contado a partir de la fecha en que se haya notificado a los peticionarios de la sentencia definitiva que agota los recursos internos (2009b, párr. 42).

Las partes sostienen una controversia sobre el cumplimiento de este requisito. La peticionaria alega que la petición fue presentada por correo postal dentro del plazo de seis meses requerido, de lo cual existe constancia en el expediente. Indica que la víctima tomó conocimiento de la resolución del Supremo Tribunal Federal sobre el Agravo de Instrumento el 18 de octubre de 2002, mediante la publicación de la decisión, y por consiguiente, enviaron la petición por correo postal a la Comisión el 18 de abril de 2003. El Estado en contraste alega que la petición fue recibida extemporáneamente ya que fue registrada por la CIDH como recibida el 25 de abril de 2003, una semana después del cierre del plazo, y que no existe constancia en el expediente de que haya sido enviada por la peticionaria el 18 de abril de 2003 (2009b, párr. 43).

En este caso, la petición data de 18 de abril de 2003 y fue registrada como recibida en la Comisión por correo postal el 25 de abril de 2003. De acuerdo a la práctica de la $\mathrm{CIDH}$ en la materia, presumiendo los días que transcurrieron mientras la petición estuvo en el correo postal, la Comisión considera que la petición fue presentada de forma oportuna (2009b, párr. 44).

En la siguiente gráfica, se puede observar el nicho citacional que podría generarse desde el espacio convencional denominado «cuál es el día de recibo de la petición cuando es enviada por correo postal».

\section{Samanta Nunes Da Silva Vs Brasil (2009b, párr.45)}

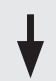

Guillermo Patricio Lynn Vs Argentina (2008e, párr. 44)

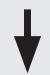

Fuente: elaboración propia tomando en cuenta los informes de admisibilidad e inadmisibilidad de la CIDH entre los años 2005 a 2011. 


\section{CONCLUSIONES}

Si bien, la Convención Americana sobre Derechos Humanos consagra en su artículo 46.1.b que para que una petición sea admitida por la Comisión deberá, entre otros requisitos, ser presentada dentro del plazo de seis meses, a partir de la fecha en que el presunto lesionado en sus derechos haya sido notificado de la decisión definitiva; en el desarrollo del presente artículo se pudo identificar y explicar las diferentes interpretaciones y aplicaciones del plazo convencional.

El término de los seis meses no implica solamente su aplicación directa y cerrada, es decir, debe ser analizado desde los diferentes elementos que el mismo correlaciona, y que deberán ser tenidos en cuenta por quien desea presentar una petición ante el sistema interamericano de protección de derechos humanos, específicamente ante la Comisión Interamericana.

Un elemento interrelacionado al plazo convencional, y que es de suma importancia para establecer su cumplimiento o no, es el agotamiento del recurso adecuado, de lo contrario la Comisión podrá declarar que la petición es inadmisible y no entrar a analizar si la denuncia fue presentada en tiempo. Pero si la víctima agota la jurisdicción interna acorde a sus obligaciones nacionales $e$ internacionales, la Comisión entrará a analizar si la petición es o no admisible, verificando si fue presentada en el plazo de los seis meses.

En otros términos, la víctima tiene la obligación de agotar el recurso que la jurisdicción interna le proporciona como idóneo o con posibilidades de efectividad, es decir, aquel que tiene la función de proteger el derecho humano presuntamente violado, y que posee la capacidad de revertir la situación jurídica infringida. Y es a partir de su notificación a la presunta víctima que se inicia a contar el plazo de los seis meses.

Sin embargo, la Comisión Interamericana abrió la posibilidad de que en los casos en los cuales se haya vencido el plazo convencional de los seis meses, se pueda hacer un análisis más riguroso de la petición en búsqueda de justicia, cual es el fin último de la Convención, en contraposición de las formalidades establecidas en el sistema procesal de peticiones individuales.

Ahora bien, la notificación según los parámetros establecidos por la Comisión puede presentarse cuando la presunta víctima tiene conocimiento de la decisión final de forma directa o por medio de su representante. Empero, cuando exista objeción por parte de los peticionarios de que el presunto lesionado no fue notificado, es el Estado quien tiene la carga procesal y probatoria de demostrar que sí lo fue.

Teniendo la fecha exacta de la notificación, la Comisión podrá establecer si la petición fue o no presentada en cumplimiento del plazo convencional de los seis meses, los cuales serán contados desde la notificación hasta el recibo de la petición por la Comisión. Sin embargo, cuando una denuncia es enviada por correo, el plazo se cuenta hasta el día de su envío, es decir, se tendrá como recibida por la Comisión el día que se remite por la agencia de correos.

No obstante lo anterior, cuando las presuntas víctimas no tengan la obligación de agotar los recursos internos porque (a) no exista en la legislación interna del Estado de que se trata el debido proceso legal para la protección del derecho o derechos que se alega han sido violados; b) no se haya permitido al presunto lesionado en sus derechos el acceso a los recursos de la jurisdicción interna, o haya sido impedido de agotarlos y c) haya retardo injustificado en la decisión sobre los mencionados recursos, la Convención establece que no será de recibo el término de los seis meses como requisito de la admisibilidad o inadmisibilidad de una petición.

Son las excepciones al agotamiento de los recursos internos en las cuales la Comisión Interamericana, en cumplimiento de su reglamento, fijó que el análisis de admisibilidad e inadmisibilidad se centrará en determinar 
si la petición fue o no presentada en un plazo razonable. Criterio que será objeto de descripción, análisis y deducción en un próximo artículo producto de la investigación «Comisión Interamericana. Aspectos Procedimentales».

\section{REFERENCIAS}

Barbosa, F. (2002). Litigio Interamericano: perspectiva jurídica del sistema de protección de derechos humanos. Bogotá D.C.: Universidad Jorge Tadeo Lozano.

Comisión Interamericana de Derechos Humanos. (2005a) Informe núm. 3/05. Petición 12.289. Admisibilidad. Guillermo Santiago Zaldívar Vs. Argentina. 22 de febrero de 2005.

--- (2005b) Informe núm. 46/05. Petición 786-03. Admisibilidad. Rainer Ibsen Cárdenas y José Luis Ibsen Peña Vs. Bolivia. 12 de octubre de 2005.

--- (2005c) Informe núm. 80/05. Petición 12.397. Inadmisibilidad. Hélio Bicudo Vs. Brasil. 24 de octubre de 2005.

--- (2006a) Informe núm. 99/06. Petición 180-01. Inadmisibilidad. Diego Rafael Jorreto Bonilla Vs. Chile. 21 de octubre de 2006.

--- Informe núm. 100/06. Petición 943-04. Inadmisibilidad. Gaybor Tapia y Colon Eloy Muñoz Vs. Ecuador. 21 de octubre de 2006.

--- (2007a) Informe núm. 50/07. Petición 23205. Admisibilidad. Carlos Baraona Bray Vs. Chile. 24 de julio de 2007.

--- (2007e) Informe núm.24/07. Petición 86001. Inadmisibilidad. Segundo Rafael Cartagena Rivadeneira Vs. Ecuador. 9 de marzo de 2007.

--- (2007d) Informe núm. 32/07. Petición 429-05. Admisibilidad. Juan Patricio Marileo Saravia y otros Vs. Chile. 23 de abril de 2007.

--- (2007c) Informe núm. 33/07. Petición 581-05. Admisibilidad. Víctor Manuel Ancalaf LLaupe Vs. Chile. 2 de mayo de 2007.
--- Informe núm. 36/07. Petición 1113-06. Admisibilidad. Personas Privadas de Libertad en las Celdas de la 76. ${ }^{\text {a }}$ Jefatura de Policía (76A DP) de Niterói, Rio de Janeiro Vs. Brasil. 17 de julio de 2007.

--- (2007b) Informe núm. 41/07. Petición 99805. Admisibilidad. Lazinho Brambilla Da Silva Vs. Brasil. 23 de julio de 2007.

--- Informe núm. 47/07. Petición 880-05. Admisibilidad. Gilberto Triana Molina Vs. Colombia. 23 de julio de 2007.

--- Informe núm. 54/07. Petición 4614-02. Admisibilidad. Wilmer Antonio González Rojas Vs. Nicaragua. 24 de julio de 2007.

--- (2008a) Informe núm. 4/08. Petición 61900. Inadmisibilidad. Jesús Vera Roncal, Daniel Zelada Abanto y Evaristo Gálvez Cárdenas Vs. Perú. 4 de marzo de 2008.

--- (2008d) Informe núm. 8/08. Caso 11.426. Admisibilidad. Marcela Alejandra Porco Vs. Bolivia. 4 de marzo de 2008.

--- (2008c) Informe núm. 27/08. Caso 11.769. A. Admisibilidad. Jesús Mónica Feria Tinta Vs. Perú. 14 de marzo de 2008.

--- (2008b) Informe núm. 47/08. Petición 86405. Admisibilidad. Luis Gonzalo «Richard Vélez Restrepo y Familia Vs. Colombia. 24 de julio de 2008.

--- Informe núm. 71/08. Petición 1290-04. Admisibilidad. José Dutra da Costa Vs. Brasil. 16 de octubre de 2008.

--- Informe núm. 72/08. Petición 1342-04. Admisibilidad. Márcio Lapoente Da Silveira Vs. Brasil. 16 de octubre de 2008.

--- (2008e) Informenúm. 69/08 Petición 68100. Admisibilidad. Guillermo Patricio Lynn Vs Argentina. 16 de octubre de 2008.

--- (2009a) Informe núm. 02/09. Peticiones 
302-04 y 386-04. Admisibilidad. J.SC.H. Y M.G.S. Vs. México. 4 de febrero de 2009.

--- Informe núm. 17/09. Petición 461-04. Admisibilidad. Adriana Victoria Plaza Orbe y Daniel Ernesto Plaza Orbe Vs. Ecuador. 19 de marzo de 2009.

--- Informe núm. 21/09. Peticiones 965-98, 638-03 y 1044-04 Acumuladas. Admisibilidad. Asociación Nacional de Cesantes y Jubilados de la SUNAT Vs. Perú. 19 de marzo de 2009.

--- (2009d) Informe núm. 20/09. Petición 23500. Admisibilidad. Agustín Bladimiro Zegarra Marín Vs. Perú. 19 de marzo de 2009.

--- Informe núm. 68/09. Petición 164-06. Admisibilidad. Wilfredo Quiñonez Barcenas y Familia Vs. Colombia. 5 de agosto de 2009.

--- Informe núm. 74/09. Petición 386-02. Admisibilidad. Mickey Alexis Mendoza Sanchez y Familia Vs. Ecuador. 5 de agosto de 2009.

--- (2009b) Informe núm. 93/09. Petición 33703. Admisibilidad. Samanta Nunes Da Silva Vs. Brasil. 7 de septiembre de 2009.

--- (2009c) Informe núm. 118/09. Petición 397-04. Inadmisibilidad. Nelson Aparecido Trindade Vs. Brasil. 12 de noviembre de 2009.

--- Informe núm. 141/09. Petición 415-07. Admisibilidad. Comunidades Agricola Diaguita de los Huascoaltinos y sus Miembros Vs. Chile. 30 de diciembre de 2009.

--- (2010d) Informe núm. 12/10. Caso 12.106. Admisibilidad. Enrique Hermann Pfister Frías y Lucrecia Pfister Prías Vs. Argentina. 16 de marzo de 2010.

--- (2010c) Informe múm. 72/10. Petición 16101. Admisibilidad. Irineo Martínez Torres y Candelario Martínez Damián Vs. México. 12 de julio de 2010.
--- (2010b) Informenúm.140/10. Petición 4357-02. Admisibilidad. Familia De José Leonardo Abril Armijos Vs. Ecuador. $1^{\circ}$ de noviembre de 2010.

--- (2010e) Informe núm. 141/10. Petición 24707. Admisibilidad. Luis Eduardo Guachalá Chimbó Vs. Ecuador. $1^{\circ}$ de noviembre de 2010.

--- (2010a) Informe núm. 150/10. Peticiones 157-99 - José Castro Ballena, María Gracia Barriga Oré Y Otras y 12.214 - Carlos Alberto Canales Huapaya Vs. Perú. Admisibilidad. 1 de noviembre de 2010.

--- Informenúm. 156/10. Petición 1368-04. Admisibilidad. Daniel Gerardo Gómez, Aida Marcela Garita y otros Vs. Costa Rica. 1 de noviembre de 2010.

--- Informenúm. 5/11. Petición 702-03. Admisibilidad. Iván Rocha Vs. Brasil. 22 de marzo de 2011.

--- (2011a) Informenúm.13/11. Petición 54804. Admisibilidad. Blanca Olivia Contreras Vital y otros Vs. México. 23 de marzo de 2011.

--- (2011b) Informenúm.17/11. Petición 27701. Inadmisibilidad. José Luis Forzzani Ballardo Vs. Perú. 23 de marzo de 2011.

--- (2011d) Informenúm.112/11. Petición 91198. Admisibilidad. Héctor Fidel Cordero Bernal Vs. Perú. 22 de julio de 2011.

--- (2011c) Informe núm. 113/11. Petición 12.125. Admisibilidad. Wilbert Apaza Vargas Vs. Perú. 22 de julio de 2011.

Convención Americana sobre Derechos Humanos. Suscrita en San José, Costa Rica 7 al 22 de noviembre de 1969.

Faúndez, H. (2004). El Sistema Interamericano de Protección de los Derechos Humanos. Aspectos Institucionales y Procedimentales. San 
José de Costa Rica: Instituto Interamericano de Derechos Humanos.

González, A. (2014). Procedimiento de Petición individual ante el Sistema Interamericano de Protección de Derechos Humanos. EnGómez, D., González, A \&Sandova, J. (EDS). Procedimientos Internacionales e Instancias Internacionales de Protección de Derechos Humanos. (p. 87- 205). Bogotá D.C: Universidad Militar Nueva Granada. López, D. (2008). El derecho de los jueces. Bogotá D.C.: Legis.

Martin, C. \&Rodríguez, D. (2006). La prohibición de la tortura y los malos tratos en el Sistema Interamericano. Manual para víctimas y sus defensores. Ginebra-Suiza: Organización Mundial contra la Tortura.

Medina, C. \&Nash, C. (2011). Sistema Interamericano de Derechos Humanos: Introducción a sus Mecanismos de Protección. Santiago de Chile: Universidad de Chile.

Comisión Interamericana de Derechos Humanos. Reglamento. Aprobado por la Comisión en su 137. ${ }^{\circ}$ período ordinario de sesiones, celebrado del 28 de octubre al 13 de noviembre de 2009.

Rey, E. \&Rey, M. (2006). Medidas Provisionales y Medidas Cautelares en el Sistema Interamericano de Derechos Humanos. Bogotá D.C.: Temis. 